\title{
DE INTERNE ACCOUNTANT
}

\author{
door A. Goudeket
}

Het is nu 16 jaar geleden, dat ik op een studiebijeenkomst van het Nederlands Instituut van Accountants een inleiding heb gehouden over de interne accountant. Sindsclien is veel gebeurd. De ontwikkeling van het accountantsberoep heeft niet stilgestaan, hetgeen uiteraard heeft meegebracht dat ook ten aanzien van functie en taak van de interne accountant van een ontwikkeling sprake is geweest. Het bedrijfsleven heeft velerlei wijzigingen ondergaan, die voor de accountantsfunctie van betekenis zijn. $\mathrm{Er}$ is beweging in de omvang van de bedrijfsformaties, in de structuur van de organisaties, in de aard van de hulpmiddelen en in de gecompliceerdheid van de externe verschijnselen waarmee de onderneming wordt geconfronteerd. In velerlei publicaties van beroepsgenoten in binnen- en buitenland is de interne accountantsfunctie direct of indirect onderwerp van bespreking geweest.

Mijn visie is door dit alles niet onbeinvloed gebleven. De eigen plaats in de beroepsuitoefening in de interne functie en het streven naar een zo goed mogelijk niveau van die uitoefening leiden tot een regelmatige bezinning op de grondslagen van functie en taak. Mijn huidige standpunt dat in de loop der jaren in regelmatig overleg met collega's in de eigen organisatie is gegroeid en door collegiaal contact met andere interne accountants en met openbare accountants nader is gevormd, wijkt af van het standpunt, dat ik in 1939 innam. Bovendien was mijn betoog in 1939 beperkt tot een bepaald facet van de interne accountantsfunctie, namelijk de vergelijking met de openbare accountant, waarbij het vraagstuk van de onafhankelijkheid in het middelpunt stond.

Op grond van het voorgaande voel ik de behoefte opnieuw van mijn opvattingen omtrent functie en taak van de interne accountant te doen blijken. Ik heb gemeend daarbij niet de ontwikkeling van mijn standpunt van het verleden naar het heden op de voet te moeten volgen, doch een beschrijving te moeten geven van de overwegingen, die achter het huidige standpunt staan.

De waarneming van het bedrijfsleven in Nederland en daarbuiten kan niet anders dan tot de conclusie leiden, dat de interne accountantsfunctie, zowel wat betreft de mate waarin ze voorkomt als haar betekenis in de onderneming, groeiende is. Men constateert daarbij, dat aan die functie in Nederland een verschillende inhoud wordt gegeven en dat de opvattingen in het buitenland afwijken van de in Nederland gegroeide.

Gezien de hierboven aangeduide evolutie van het bedrijfsleven en van het beroep lijkt een voortdurende bezinning op deze verschijningsvorm van de beroepsuitoefening mij doelmatig. Dit geldt zowel voor de interne als voor de openbare accountant. Voor de interne accountant, omdat dit een leidraad kan zijn bij zijn streven naar een zo rationeel mogelijke bepaling van functie en taak binnen de onderneming en voor zijn contact met de openbare accountant. Voor de openbare accountant, omdat hij in de beroepsuitoefening steeds meer wordt geconfronteerd met organisaties waarin de interne accountantsfunctie voorkomt; dit laatste kan het gevolg zijn van zijn verlangen dat een interne accountantsfunctie wordt ingesteld om tot een rationele uitoefening van zijn eigen functie te komen. Het spreekt vanzelf, dat voor een rationele samenwerking met de interne functie een nor- 
matieve opvatting omtrent functie en taak van de interne accountant belangrijk is.

Moge ook te dien aanzien dit opstel een bijdrage leveren.

Het werkgebied van de interne accountant is de onderneming. Aan het feit, dat de interne accountant ook in overheidsbedrijven optreedt meen ik te kunnen voorbijgaan, omdat het onderscheid in het kader van deze beschouwing niet van betekenis is. Alvorens op de accountantsfunctie in te gaan is het noodzakelijk, eerst het werkgebied nader in ogenschouw te nemen.

Dit is daarom zo van belang omdat ik uitdrukkelijk wens voorop te stellen, dat ik de economische rechtvaardiging van de interne accountantsfunctie niet ontleen aan onvolkomenheden in de organisatie van de onderneming, maar aan de structurele behoefte. De leiding valt uiteen in de elementen constitueren (het bepalen van de bedrijfspolitiek), dirigeren (het geven van instructies) en controleren (het toezien op de juiste uitvoering van de instructies). De organisatie van de onderneming moet in zichzelf een gesloten geheel vormen en alle waarborgen van controle bieden, die structureel binnen het kader van de mogelijkheden liggen.

De accountantscontrole vormt niet een element van het organisch verband in de onderneming. De plaats van de accountant in het organisatieschema moet in overeenstemming zijn met de inhoud van zijn functie, dat is, de controle ten behoeve van de leiding. Wil de accountant namelijk kunnen voorzien in de structurele tekortkoming van de organisatie voor wat betreft de controle, waarop hierna nader zal worden teruggekomen, dan moet hij los van het organisch verband staan.

Zowel bij de constituerende als bij de dirigerende en controlerende taak van de leiding vormt de administratie in haar moderne conceptie een essentiële functie. De registratie van het bedrijfsgebeuren, de berichtgeving voor de diverse niveau's van leiding en de daarbij behorende analyse van de resultaten en het vermogen, de conceptie van de administratieve organisatie en het aangepast houden van die organisatie aan de behoeften van de onderneming maken de administrateur tot de architect en de uitvoerder van de bevrediging van de behoeften van de leiding op het gebied van de bedrijfseconomie en de interne controle. In het kader van deze beschouwing wordt niet nader ingegaan op de verbijzondering, die in de administratieve functie kan voorkomen, evenmin op de plaats van die functie in de organisatie; het gaat hier slechts om de inhoud dier functie in een organisatie, die aan de eisen voldoet. Wel wens ik op te merken, dat ik in de Nederlandse sfeer geen behoefte heb aan het woord „controller". Weliswaar is het woord afgeleid van ".control" in de zin van de activiteit van de leiding gericht op de waarborg, dat haar bedrijfspolitiek wordt nagekomen, doch het wekt verwarring in twee richtingen. Enerzijds omdat het ,.controle" indiceert in een betekenis, die niet bij deze functie doch bij de verbijzonderde controlefunctie past, anderzijds omdat het bedrijfsleven zou denken, dat van iets geheel nieuws sprake is, terwijl het in werkelijkheid alleen gaat om de vervolmaking van een sinds lang bestaande essentiële functie in iedere onderneming. De onderneming in wier organisatieschema een ,controller" voorkomt is daardoor niet beter georganiseerd, doch wel kan men zeggen, dat een onderneming waar de inhoud van de administratieve functie niet aan de eisen voldoet niet goed is georganiseerd. Internationaal hebben wij weliswaar behoefte aan eenvormigheid van de begrippen, maar zolang wij nog niet aan één wereldtaal toe zijn, zullen wij met verschillende woorden voor dezelfde begrippen moeten werken. Met het sinds decennia ingeburgerde

m a b blz, 196 
woord accountant is door het gebruik daarvan in de Angelsaksische landen reeds voldoende mogelijkheid tot verwarring geschapen!

Hoe volkomen de organisatie van de onderneming moge zijn, voor de leiding blijft in het kader van haar controlerende taak een behoefte onvervuld. De administratie vervult een executieve functie omdat $z \mathrm{ij}$, in het bedrijfseconomische vlak, deel heeft aan de totstandkoming van de beleidsbesluiten. Reeds daardoor zal zij niet de behoefte aan controle volledig kunnen dekken. Bovendien zal de leiding controle wensen op de wijze waarop de administratieve functie wordt vervuld, waarbij de doelmatigheid en de juistheid van de berichtgeving een belangrijke plaats innemen. In deze behoefte wordt voorzien door de accountantscontrole, hetzij die van de openbare of van de interne accountant. Tot een bepaald stadium in de ontwikkeling van de onderneming werd deze functie door de openbare accountant vervuld; de controle ten behoeve van de leiding en van het maatschappelijk verkeer vielen hier samen. Door de grotere gecompliceerdheid en de omvang van de ondernemingen en de daardoor meer dan evenredige toeneming van het controleprobleem ontstond in de onderneming behoefte aan een eigen orgaan voor de accountantscontrole, de interne accountant. Die behoefte vloeit voort uit de noodzakelijkheid om voor een doelmatige vervulling van de accountantsfunctie dichter bij het specifieke van de onderneming te staan, voorts de wenselijkheid voor de leiding om de accountantsdeskundigheid bij voortduring ter beschikking te hebben, terwijl ook economische overwegingen, namelijk het afwegen van nut en offers een rol kunnen spelen. Deze ontwikkeling, liggende in de onderneming, loopt parallel met de overwegingen van de openbare accountant, die door een te sterke binding aan één onderneming van accountants en assistenten bezwaren gaat zien voor de eigen organisatie uit hoofde van te geringe spreiding in het arbeidsveld en met het oog op de economische onafhankelijkheid.

Alvorens nader op functie en taak van de interne acountant in te gaan moet aan enige vraagstukken van algemene betekenis aandacht worden besteed.

Het is van groot belang, dat generlei twijfel bestaat over de vraag of in een onderneming waar een aan alle eisen voldoende interne accountantscontrole wordt uitgevoerd, ook nog behoefte bestaat aan de openbare accountant. Deze vraag wordt zonder enig voorbehoud bevestigend beantwoord. Het feit, dat de interne accountant ten principale wat betreft de deskundigheid op het gebied van de bedrijfseconomie, de administratieve organisatie en de controle op hetzelfde niveau staat als de openbare accountant en dat hij door het lidmaatschap van dezelfde beroepsorganisatie is onderworpen aan hetzelfde tuchtrecht doet daaraan niets af. De behoefte van het maatschappelijk verkeer, dat om het oordeel van een onafhankelijk accountant vraagt, is bepalend. De interne accountant kan als zodanig niet worden geacht een dergelijk oordeel te kunnen geven, en wel door zijn functionele gebondenheid aan de leiding van de onderneming.

Een uit het aanwezig zijn van de openbare accountant voortvloeiend gevolg, behoudens de andere facetten van de samenwerking met de openbare accountant waarop hierna nader zal worden ingegaan, is, dat de interne accountant bij de vervulling van zijn functie aan dat blote feit kracht ontleent. Het is daarbij irrelevant of de openbare accountant de facto ooit moet optreden om de interne accountant bij de vervulling van zijn taak bij te staan.

$\mathrm{Bij}$ het vorenstaande komen twee problemen naar voren, namelijk dat van de onafhankelijkheid en van de duplicering van werkzaamheden. 
Het vraagstuk van de onafhankelijkheid is de grote moeilijkheid geweest bij mijn inleiding in 1939. Het heeft zijn stempel gedrukt op vele van mijn stellingen, culminerende in de uitspraak, dat het onderscheid ,intern" en "extern" van formele betekenis is. Bij de discussies is mij te dien aanzien de kritiek niet gespaard. Zoals ik het nu zie, terecht. Ten aanzien van de inhoud van het begrip ,,onafhankelijkheid" ben ik nog steeds dezelfde mening toegedaan als toentertijd: onafhankelijkheid is in de eerste plaats een geestesgesteldheid, een karaktereigenschap; indien men dat niet in zich heeft. heeft de verschijningsvorm niet eens praktische betekenis. Zoals gezegd kwalificeerde ik toen het onderscheid in ,intern" en ,extern" in de beroepsuitoefening als te zijn van formele aard; dat was fout. Het gaat veeleer om een functioneel onderscheid. De interne accountant ontleent de inhoud van zijn functie aan de leiding van de onderneming, de openbare accountant aan het maatschappelijk verkeer. Dat de functie met dezelfde vakbekwaamheid wordt vervuld en ook overigens onder dezelfde voorwaarden wordt bedreven, doet niet af aan het wezenlijke verschil, voortspruitende uit de oorsprong van de functie, namelijk hetzij ingesteld door de leiding van de onderneming en dus gepaard gaande met gebondenheid aan die onderneming, of ontleend aan het maatschappelijk verkeer met als voorwaarde de vrije beroepsuitoefening. Ook het feit, dat bij de creatie van de interne accountantsfunctie de leiding zich bewust moet zijn een deskundige aan te stellen, bij wier het onafhankelijke oordeel tot het karakteristieke van de functie behoort, doet daaraan niets af.

Ten aanzien van het vraagstuk van de duplicering van werkzaamheden staat vast, dat bij een volkomen controle, uitgevoerd door de interne accountant, de openbare accountant - om tot een zelfstandig oordeel te komen - bepaalde door de interne accountant uitgevoerde controlewerkzaamheden moet herhalen. Zo al van herhaling van controlehandelingen kan worden gesproken, toch is naar mijn mening niet van duplicering sprake in de zin van tweemaal hetzelfde doen. Daarvan mag alleen worden gesproken, indien de doelstelling van die handelingen gelijk is. Dit is hier niet het geval. De doelstelling van de openbare accountant bij die handelingen is: in het kader van zijn volkomen controle vast te stellen of de interne accountantscontrole goed functioneert; die van de interne accountant: de werkzaamheden in het kader van zijn volkomen controle te verrichten. Ook in economische zin is de herhaling van bepaalde controlehandelingen irrelevant, omdat het uiteindelijk gaat om de vraag of de controlebehoeften van de leiding van de onderneming en die van het maatschappelijk verkeer beide op de meest economische wijze worden bevredigd, dat wil ook hier zeggen een afwegen van nut en offers.

Een ander vraagstuk dat niet onbesproken mag blijven is of een accountant, die in een onderneming de functie van interne accountant vervult, hetzij voor die onderneming, met vermelding van kwaliteit, of voor een andere onderneming, als openbaar accountant in de publieke sfeer mag treden. Het eerste deel van de vraag is opgelost. In aansluiting op de Ereregelen van het N.I.v.A. heeft de Commissie van Advies in Beroepsaangelegenheden zich met dit vraagstuk bezig gehouden en het Bestuur geadviseerd de desbetreffende leden aan te bevelen niet als interne accountant in de publieke sfeer te treden en de C.A.B. op te dragen hierop toe te zien en door collegiaal overleg te trachten afwijkingen te voorkomen. Het Bestuur heeft het advies van de C.A.B. gevolgd; in een ledenbijeenkomst werd aan het advies aandacht besteed. Ik ben het met dit besluit volkomen eens. Het is 
bevorderlijk voor de zuiverheid van de interne accountantsfunctie en daardoor doelmatig voor de vervulling daarvan.

Het tweede deel van de vraag is nog open. Het is in bepaalde kringen nu en dan aan de orde geweest. Een uitspraak van officiële beroepsinstanties is er op dit moment nog niet. Ik ben van mening, dat de interne accountant zich van geval tot geval ernstig moet beraden of er uit hoofde van de omstandigheden aanleiding bestaat niet als openbaar accountant op te treden ter vermijding van enigerlei inbreuk op de onvoorwaardelijk in stand te houden onafhankelijkheid van de accountant of wegens de onmogelijkheid voor hem om tot een onbevangen oordeel te komen. De interne accountant moet zich bovendien realiseren, dat hij een richting heeft gekozen, die uit collegiale overwegingen niet tezamen behoort te gaan met een onbeperkte vrije beroepsuitoefening. Ik zie echter geen aanleiding voor een reglementaire bepaling, die er op zou zijn gericht een interne accountant te verbieden ooit als openbaar accountant op te treden, omdat dit voor de interne accountant tot een niet te verantwoorden beperking van activiteit zou kunnen leiden.

\section{Functie.}

Leiden bestaat, zo zagen wij, uit drie elementen: het bepalen van de bedrijfspolitiek, het geven van instructies en het toezicht op de uitvoering. In het kleine bedrijf liggen deze elementen in het algemeen ongesplitst in handen van de leiding. Naarmate het bedrijf groeit zal steeds meer delegatie van werkzaamheden aan anderen plaats vinden. Het controlerend element van de leiding zal daardoor in belangrijkheid toenemen.

In het kader van haar controlerende taak moet de leiding de zekerheid hebben, dat:

(a) de door haar gegeven opdrachten juist worden uitgevoerd en de door haar gedelegeerde bevoegdheden niet worden overschreden;

(b) de haar verstrekte informatie omtrent hetgeen werd bereikt in overeenstemming is met de werkelijkheid;

(c) de normen, waaraan het in feite bereikte wordt getoetst, aan de eisen voldoen.

Bij het groter worden van het bedrijf en de mede daardoor toenemende gecompliceerdheid, is de leiding in stijgende mate aangewezen op de administratie, die door haar taak op het gebied van registratie, berichtgeving en analyse gedeeltelijk in de controlebehoefte van de leiding voorziet. De administratie kan daarin slechts ten dele voorzien, omdat zij in het bedrijfseconomische vlak zelf aan het bedrijfsgebeuren deelneemt en dus niet onbevangen is en omdat de leiding ook ten aanzien van de administratieve gegevens via dewelke zij het bedrijfsgebeuren waarneemt, zekerheid wenst. Vanuit deze ontwikkeling is in het bedrijf de behoefte aan accountantscontrole gegroeid. Tot een bepaalde bedrijfsomvang voorziet de openbare accountant in deze behoefte; bij verdere groei van het bedrijf is de aanstelling van een accountant in vaste dient, de interne accountant, de rationele oplossing van het vraagstuk. De interne accountant is dus een gedifferentieerde functie van de leiding. De inhoud van de functie wordt ontleend aan de leiding. $\mathrm{H}_{\mathrm{ij}}$ is een deskundig controlerend vertrouwensman van de leiding op het gebied van de administratieve organisatie en de bedrijfseconomie.

In dit verband moet onder het oog worden gezien wat de hiërarchische 
plaats van de interne accountant in de onderneming behoort te zijn. In het algemeen kan worden gesteld, dat hij direct onder het hoogste orgaan in de onderneming moet worden geplaatst, dat wil zeggen, onder de directie. Dit is een noodzakelijke consequentie van de aard van de functie, namelijk de gedelegeerde van de leiding op het gebied van de controle op een bepaald vlak. Uit praktische overwegingen geef ik de voorkeur aan de plaatsing onder de president-directeur, omdat daarmede wordt vermeden, dat hij steeds aan de gehele directie zou moeten rapporteren en voor hem geen conflict ontstaat, indien hij zich niet bevredigd voelt na zich tot een van de leden van de directie te hebben gewend. Iedereen weet dan namelijk, dat de interne accountant zich uiteindelijk tot de president kan wenden. In de Verenigde Staten komt het veelvuldig voor, dat de interne accountant onder de ,controller" staat. Door de conceptie van de interne accountantsfunctie aldaar is dit begrijpelijk, doch onjuist. Uit de literatuur blijkt, dat deze materie nog in beweging is en stemmen opgaan, die stellen, dat de .,president" de aangewezen chef voor de interne accountant is. In de $\mathrm{Ne}$ derlandse opvattingen past in het algemeen slechts een plaatsing direct onder de hoogste leiding, dat wil zeggen onder de directie.

Taak.

Er moet dus aandacht worden besteed aan de vraag welke arbeid het verbijzonderde controle-orgaan, de interne accountant, moet verrichten om de leiding de zekerheden, zoals onder "functie" opgesomd, te verschaffen.

ad (a) Daartoe zal de interne accountant er op moeten toezien, dat een zodanige organisatie wordt geschapen, dat hij kennis krijgt van het door de leiding gewenste bedrijfsbeleid, de gedelegeerde bevoegdheden en de gegeven opdrachten. Hij heeft deze wetenschap nodig om in staat te zijn controle uit te oefenen op de uitvoering van de opdrachten en het blijven binnen het kader van de bevoegdheden.

ad (b) De interne accountant zal al die controles moeten uitvoeren, welke noodzakelijk zijn om vast te stellen, dat de berichtgeving in overeenstemming is met de werkelijkheid. Dit houdt mede in, dat hij zal moeten vaststellen, dat de functionele arbeidsverdeling aan de eisen blijft voldoen en dat hij zich doorlopend moet overtuigen van de werking van de interne controle.

ad (c) Hiertoe zal de interne accountant de aanvaardbaarheid moeten vaststellen van hetgeen in de berichtgeving voor de verschillende niveau's van ",management" als ,bereikbaar (= budget)" wordt aangegeven. Hij zal periodiek moeten nagaan of de voor het budget noodzakelijke verantwoordelijkheden doelmatig over de functies zijn verdeeld.

Zuiver technische en commerciële problemen onttrekken zich uiteraard aan het directe oordeel van de interne accountant, maar via de confrontatie van voor- en nacalculatie, vergelijkingen in de tijd, bedrijfsvergelijkingen, bestudering van de functionele scheiding en dergelijke zal hij zich voor eigen taakvervulling ook over de technische en commerciële organisatie en taakstelling een zodanig oordeel kunnen vormen als van een nietterzake deskundige mag worden verwacht.

De vaktechnische eisen voor de arbeid van de interne accountant zijn gelijk aan die van de openbare accountant en het spreekt dus wel vanzelf, dat de voor een rationele vervulling van de functie noodzakelijke taak - in het voorgaande in afzonderlijke elementen beschouwd - is saam te vatten 
in de controle van de interne jaarrekening. Die jaarrekening vormt het sluitstuk van het organisch verband tussen de bedrijfshandelingen, het is de basis voor de door de leiding af te leggen verantwoording. Uit het vorenstaande vloeit voort, dat ook de bedrijfshandelingen van de hoogste bestuursorganen in de controle moeten worden betrokken.

Vanuit de functie van de interne accountant, deskundig controlerend vertrouwensman van de leiding op het gebied van de administratieve organisatie en de bedrijfseconomie, werd de taak concluderend saamgevat als de controle van de interne jaarrekening. De vraag moet onder het oog worden gezien of alleen in dat geval van een interne accountant mag worden gesproken, dan wel of ook van een dergelijke functie sprake is indien de taak zich tot deelgebieden beperkt, bij voorbeeld indien de taak bestaat uit het controleren van dochterondernemingen of van bepaalde onderdelen van de onderneming. Ik ben van mening, dat deze vraag bevestigend moet worden beantwoord. Het gaat er slechts om, dat de werkzaamheden voortvloeien uit een taak, die in het algemeen door een accountant kan worden aanvaard.

Wanneer wij in verband met functie en taak naar Engeland en Amerika kijken dan valt te constateren, dat - niettegenstaande analogie in de functie kan worden vastgesteld - bij de taak essentiële verschillen bestaan. Deze verschillen zijn een logisch gevolg van de aldaar heersende opvatting ten aanzien van de taak van de accountant in het algemeen, die afwijkt van de Nederlandse opvatting. In de literatuur in die landen vindt men naast op zichzelf niet oninteressante taakomschrijvingen van de interne accountant tot slot praktisch steeds de uitspraak, dat de interne en de openbare accountant volgens dezelfde technieken werken, doch dat de interne accountant zich richt op de organisatie en de uitvoering, terwijl de openbare accountant de jaarrekening tot controle-object heeft. De betekenis van de interne accountant voor de openbare is, dat door diens aanwezigheid de openbare accountant tot een vermindering van het detailwerk, gericht op de toetsing van de goede werking van de interne controle, kan komen. Het zou te ver voeren, in het kader van dit opstel daarop nader in te gaan, omdat daarbij niet zou kunnen worden gemist een vergelijkende beschouwing van de controle-opvattingen in het algemeen aldaar en bij ons.

Aangezien, zoals eerder werd gesteld, de interne accountant de inhoud van zijn functie aan de leiding van de onderneming ontleent, komt de vraag op of en in welke omvang de leiding invloed kan uitoefenen op de uit die functie voortvloeiende taak. Op de inhoud van de functie kan de leiding ten principale invloed uitoefenen. De enige beperking te dien aanzien is, dat de functie een zodanige inhoud moet hebben, dat de accountant die functie vanuit vaktechnisch gezichtspunt kan aanvaarden. Op de taak kan de leiding principieel geen invloed uitoefenen, omdat het de accountant zelve moet zijn, die bepaalt welke werkzaambeden moeten worden verricht om de verantwoordelijkheid voor de uitkomst van de arbeid te kunnen dragen.

In het adviserende vlak heeft de interne accountant ten behoeve van de leiding van de onderneming een belangrijke taak. Op grond van zijn deskundigheid zal het vaak doelmatig zijn, dat hij voor het uitbrengen van een advies wordt ingeschakeld. Door zijn functie staat hij los van de dagelijkse gang van het bedrijfsgebeuren, hij zal dus een onbevangen oordeel geven, hetgeen hem ook uit dien hoofde tot de aangewezen functionaris maakt om de verschillende organen in de onderneming van advies te dienen. Het spreekt vanzelf, dat zich omstandigheden kunnen voordoen, dat de openbare accountant de aangewezen instantie is voor een uit te brengen ad- 
vies. De interne accountant moet ook hier zorgen de ware vertrouwensman van de leiding te zijn, dat wil zeggen, dat hij in daartoe aanleiding gevende gevallen het initiatief neemt om de openbare accountant in te schakelen.

De vraag of de interne accountant voor de onderneming investigations kan uitvoeren moet mijns inziens in principe bevestigend worden beantwoord. Hij behoeft in deze niet ten achter te staan bij de openbare accountant. Enerzijds kan de grondige kennis van het specifieke in de branche hem ten dienste staan, anderzijds kan het voorkomen, dat de mate waarin hij door de interne functie eenzijdig is gericht, hem de breedheid van ervaring, nodig om bepaalde investigations uit te voeren, doet missen, Het kan uit concurrentie-overwegingen uiteraard ook voorkomen, dat de derde de voorkeur geeft aan een accountant, die in het vrije beroep werkzaam is.

\section{Verhouding tot de openbare accountant.}

In aansluiting op hetgeen werd opgemerkt omtrent de algemene betekenis van de aanwezigheid van de openbare accountant voor de interne accountant valt over de verhouding tot de openbare accountant het volgende op te merken.

De openbare accountant zal zich bij de conceptie van het programma van zijn werkzaamheden ten behoeve van de vervulling van zijn opdracht, uitgaand van de doelstelling en de vaktechnische eisen, baseren op de organisatie, die hij in de onderneming aantreft. Een van de elementen van die organisatie is de interne accountantsfunctie. In zijn controleprogramma zullen dus zijn opgenomen de werkzaamheden verband houdend met het onderzoek of de interne functie zodanig is georganiseerd, dat de grondslagen voor een juiste vervulling van die functie aanwezig zijn en of die organisatie bij voortduring aan de te stellen eisen blijft voldoen. Verder de werkzaamheden met betrekking tot het onderzoek naar de wijze waarop de taak door de interne accountant wordt verricht, omdat de zekerheid omtrent de uitkomst van diens arbeid een van de grondslagen is van zijn certificaat bij de jaarrekening.

Bij dit onderzoek zal de openbare accountant zich allereerst interesseren voor de plaats, die de interne accountant in de organisatie inneemt. Hierbij gaat het om de vaststelling, dat die plaats een zodanige is, dat de onafhankelijkheid van de interne accountant, voor zover zulks binnen de onderneming mogelijk is, wordt gewaarborgd. Uit het voorafgaande blijkt voldoende onder welke omstandigheden schrijver dezes van mening is, dat in dit opzicht aan de eisen wordt voldaan. Verder is van belang welke de antecedenten zijn van de leiding van de interne functie. Hierop wordt in het navolgende nader ingegaan.

Ten aanzien van het onderzoek naar de wijze waarop de taak is verricht, moet de openbare accountant de zekerheid hebben, dat uit de functie-omschrijving van de interne accountant blijkt, dat deze de verplichting heeft de uitkomst van zijn arbeid onverkort ter kennis te brengen van de openbare accountant; opdat de openbare accountant in rationele mate van de uitkomst van de arbeid van de interne accountant gebruik zal kunnen maken, is het noodzakelijk, dat de openbare accountant zich met het controleprogramma van de interne accountant kan verenigen. Ten aanzien van de uitvoering vormen de dossiers met werkstaten en de rapporten van de interne accountant essentiele gegevens.

Het valt buiten het bestek van dit opstel aandacht te besteden aan de specifieke arbeid, die de openbare accountant moet verrichten ten behoeve 
van de vorming van zijn eigen oordeel. Voor de goede orde zij hier opgemerkt, dat de controle op de leiding voor wat betreft de samenstelling van de externe jaarrekening op basis van de interne jaarrekening tot het specifieke terrein van de openbare accountant behoort.

De interne accountant heeft dus in de eerste plaats verantwoordelijkheid tegenover de leiding van de onderneming, doch daarnaast in overeenstemming met de opdracht van die leiding, ook tegenover de openbare accountant met name dat zijn controle overeenkomstig de daaraan te stellen vaktechnische eisen wordt verricht en dat hij de uitkomst van zijn controle onverkort ter kennis van de openbare accountant brengt.

\section{Vereisten ten aanzien van de interne accountant.}

De interne accountant zal zijn functie slechts rationeel kunnen vervullen, indien zijn opleiding voldoende waarborgen voor deskundigheid biedt, dat wil zeggen dat hij in het bezit moet zijn van de volledige accountantsbevoegdheden en over de noodzakelijke praktische ervaring moet beschikken. Het lidmaatschap van een van de erkende beroepsorganisaties en de daaruit voortvloeiende onderworpenheid aan reglementen en sancties zijn voor de vervulling van zijn functie binnen de onderneming, zo al niet in de mate als voor de openbare accountant in verband met diens functie in het maatschappelijk verkeer, toch essentieel. Dit brengt en houdt hem in de sfeer van onafhankelijkheid, die het beroep van de accountant kenmerkt. Ook in het kader van de samenwerking met de openbare accountant is het lidmaatschap van een erkende beroepsorganisatie noodzakelijk, omdat alleen in dat geval de openbare accountant in rationele mate gebruik zal kunnen maken van de verklaringen van de interne accountant. Vaak heeft het lidmaatschap een psychologische invloed op de houding van de gecontroleerde en vergemakkelijkt daardoor de positie van de interne accountant. Dit is van belang, omdat de controlefunctie nu eenmaal zekere, de rationele vervulling van de functie storende, gevoelens kan opwekken, zelfs bij degenen die de functie uit economische overwegingen hebben gecreëerd.

Tot slot wens ik er nog op te wijzen dat het interessant is, de problematiek met betrekking tot de interne accountant te benaderen langs de weg van de analogie met die van de openbare accountant. Deze laatste in zijn functie ontleend aan het maatschappelijk verkeer, de interne functie als ontleend aan de leiding van de onderneming. Aldus handelende komt men tot de logische omschrijving van functie en taak van de interne accountant. Dit leidt tot de mogelijkheid van een harmonische samenwerking tussen beiden, hetgeen tot een rationele vervulling van de accountantsfunctie in het bedrijfsleven leidt. 